\title{
Nephroprotective Effect of Pentoxyphylline Through Improvement in the Expression of TGF- $\beta 1$, Collagen Type-1, and Renal Interstitial Fibrosis in Swiss Strain Mice After Being Induced by Doxorubicin
}

\author{
Bambang Purwanto', A. Guntur H. ${ }^{2}$
}

'Sub Division of Renal Hypertension, Faculty of Medicine, UNS/RSUD Dr. Moewardi Surakarta

${ }^{2}$ Sub Division of Tropical Infection and Immunology, Faculty of Medicine, UNS/RSUD Dr. Moewardi Surakarta

\section{Abstract}

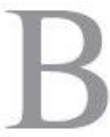

ACKGROUND: Use of doxorubicin (DXR) in the treatment of cancer has been increasing along with the increase in cancer morbidity. Nephrotoxic effects of DXR are still a probelm. Pentoxyphylline (PTX) as an electron-donor material can be nephroprotective, so the combination of DXR and PTX might reduce the nephrotoxic effects of DXR. The aim of this tudy was to prove the nephroprotective effect of PTX and DXR nephrotoxicity through the improvement of TGF- $\beta 1$, collage type-1, and renal interstitial fibrosis.

METHODS: Twenty-four males Swiss strain mice, divided into three groups namely Control (C) injected with $\mathrm{NaCl}$ $0.9 \%$; DXR induced nephrotoxicity (D); and effect of PTX on $\mathrm{D}(\mathrm{P} / \mathrm{D})$ by intraperitoneally, respectively, each group consisted of 8 mice. Injections were given once a week for three consecutive weeks. At 8 th week post-treatment, all eight mice of each group were sacrificed. Examination of TGF- $\beta 1$ and collagen type-I expression was done by immunohistochemistry with monoclonal antibody. Renal interstitial fibrosis examination was done by a histopathologist, using Verheoff van Giesen staining. The statistic analysis was carried out using one-way ANOVA.

RESULTS: TGF- $\beta 1$ expression increased from $C$ to $D$ and subsequently decreased in $\mathrm{P} / \mathrm{D}(4.50 \pm 3.89$ vs $177.88 \pm 68.78$ vs $36.88 \pm 9.51$ ). Collagen type-I expression increased from
$\mathrm{C}$ to $\mathrm{D}$ and subsequently decreased in $\mathrm{P} / \mathrm{D}(12.00 \pm 14.32$ vs $186.25 \pm 125.62$ vs $36.00 \pm 29.14)$. Renal interstitial fibrosis expression increased from $\mathrm{C}$ to $\mathrm{D}$ and subsequently decreased in P/D $(16.75 \pm 6.14$ vs $85.00 \pm 7.33$ vs $60.50 \pm 11.40$ ). The expression of TGF- $\beta 1$, collagen type-1, and renal interstitial fibrosis were higher significantly in D group as compared to $\mathrm{C}$ group ( $\mathrm{p}<0,001$ ). The expression of TGF- $\beta 1$, collagen type- 1 , and renal interstitial fibrosis were lower significantly in P/D group as compared to D group ( $\mathrm{p}<0.005)$.

CONCLUSIONS: PTX was proved to be nephroprotector inducing by DXR.

KEYWORDS: PTX, nephroprotector, TGF- $\beta 1$, collagen type-I, renal interstitial fibrosis.

\section{Introduction}

According to WHO, deaths from cancer worldwide will increase from time to time. The death toll due to cancer is estimated to be 12 million in the year $2030,30 \%$ of which can actually be prevented (1). Doxorubicin (DXR) is very widely used in cancer treatment, but its side effect that is destructive to kidney cells (nephrotoxic) remains an important issue that has not yet been much studied. The side effect is caused by reactive oxygen species (ROS), which is highly reactive commonly resulting as DXR reaction 
in cancer therapy. ROS damages the proximal tubule cells, endothelials, basal membrane, mesangial cells, and visceral glomerulus cells. Damaged cells (debris) activate macrophages through Toll-Like Receptor 4 (TLR4), so the macrophages will express cytokines, including TNF- $\alpha 1$, TGF- $\beta 1$, IL- $1 \beta$, IL- 6 , and IL-8 $(2,3)$.

TGF- $\beta 1$ regulates cell proliferation and differentiation, embryonic development, wound healing, and angiogenesis. TGF- $\beta 1$ also suppresses immune system and stimulates extracellular matrix components. Excessive TGF$\beta 1$ production may cause too much accumulation of extracellular matrix, scarring and fibrosis that finally result in tissue damage (4). TGF- $\beta 1$ binding to renal interstitial fibroblast cells membrane receptor stimulates excessive expression of collagen type- 1 and interstitial fibrosis $(5,6)$. In this study, we used TGF- $\beta$ as a progress marker towards interstitial fibrosis in renal tissue.

Pentoxyphylline (PTX) is a derivative of metilxanthin, which can provide electron (electron donor) as an antiROS. So PTX is a nephro-protective material, which can protect kidney cells from the destructive effect of nephrotoxic material $(7,8,9,10)$. The aim of this study was to prove the nephroprotective effect of PTX against DXR nephrotoxicity through improvement of TGF- $\beta 1$, collagen type-1, and renal interstitial fibrosis.

\section{Methods}

The design of this study was pure experimental. The study samples comprised 24 male mice strain Swiss. The mice were aged 3-4 months and weighed 20-30 grams. They were divided into three groups: Control (C), DXR induced nephrotoxicity (D), and effect of PTX on D (P/D). The Federer formula was used to determine the number of mice for the experiment, i.e.: $(t-1)(r-1)<15$, where $t=$ the number of group, $r=$ the number of sample. Each group consisted of eight mice.

The $\mathrm{C}$ group was injected with $0,2 \mathrm{ml} 0,9 \% \mathrm{NaCl}$ intraperitoneally (ip), D group with $0,038 \mathrm{mg}$ DXR $/ 20 \mathrm{~g}$ body mass by ip, and P/D group with $0,038 \mathrm{DXR} / 20 \mathrm{~g}$ body mass $+1,6 \mathrm{mg}$ PTX $/ 20 \mathrm{~g}$ body mass by ip. Injection was done once a week for three weeks. At week 8 post treatment, all mice in each group were killed by cervical dislocation. Kidney tissues were taken and made into histological preparations according to the standard methods of the Pathology Laboratory, Medical Faculty, Airlangga University, Surabaya, Indonesia.

Each sample of kidney tissue was made histological preparations. We made 3 slides from each for immunobiological examination. From each sample, one slide was stained with Verheoff van Giesen (VvG) staining technique for the determination of interstitial fibrosis. Renal interstitial fibrosis thickness was measured using a micrometer which was calibrated beforehand at 400x magnification. Data obtained from each treatment represented the average value of five different fields of view. Whereas, two other slides were used for immunobiological examination by immunohistochemistry methods using monoclonal antibody against TGF- $\beta 1$ and collagen type- 1 . Assessment and measurement of TGF- $\beta 1$ and collagen type-1 expression were done by counting the number of cells per 1000 immunoreactive cells on macrophage cell surfaces to TGF- $\beta 1$ and fibroblast cells to collagen type- 1 . Data were analyzed using ANOVA test, with SPSS program, to get the differences between TGF- $\beta 1$, collagen type-1, and interstitial fibrosis expression in normal circumstances, nephrotoxic, and nephroprotective at week 8 post treatment.

\section{Results}

\section{TGF- $\beta 1$ and collagen type-1 expression in kidney tissue}

The results showed that mean of TGF- $\beta 1$ expression was higher significantly in DXR as compared to C (177.88 vs. $4.50 ; \mathrm{p}<0.001$ ); and addition of PTX to DXR showed significantly lower than in DXR (36.88 vs. 177.88 ; $\mathrm{p}<0.001$ ) (Figure 1).

Results of TGF- $\beta 1$ expression 8 weeks after treatment, performed by immunohistochemical examination on the membrane of macrophage cells using light microscope, are shown in Figure 2. 


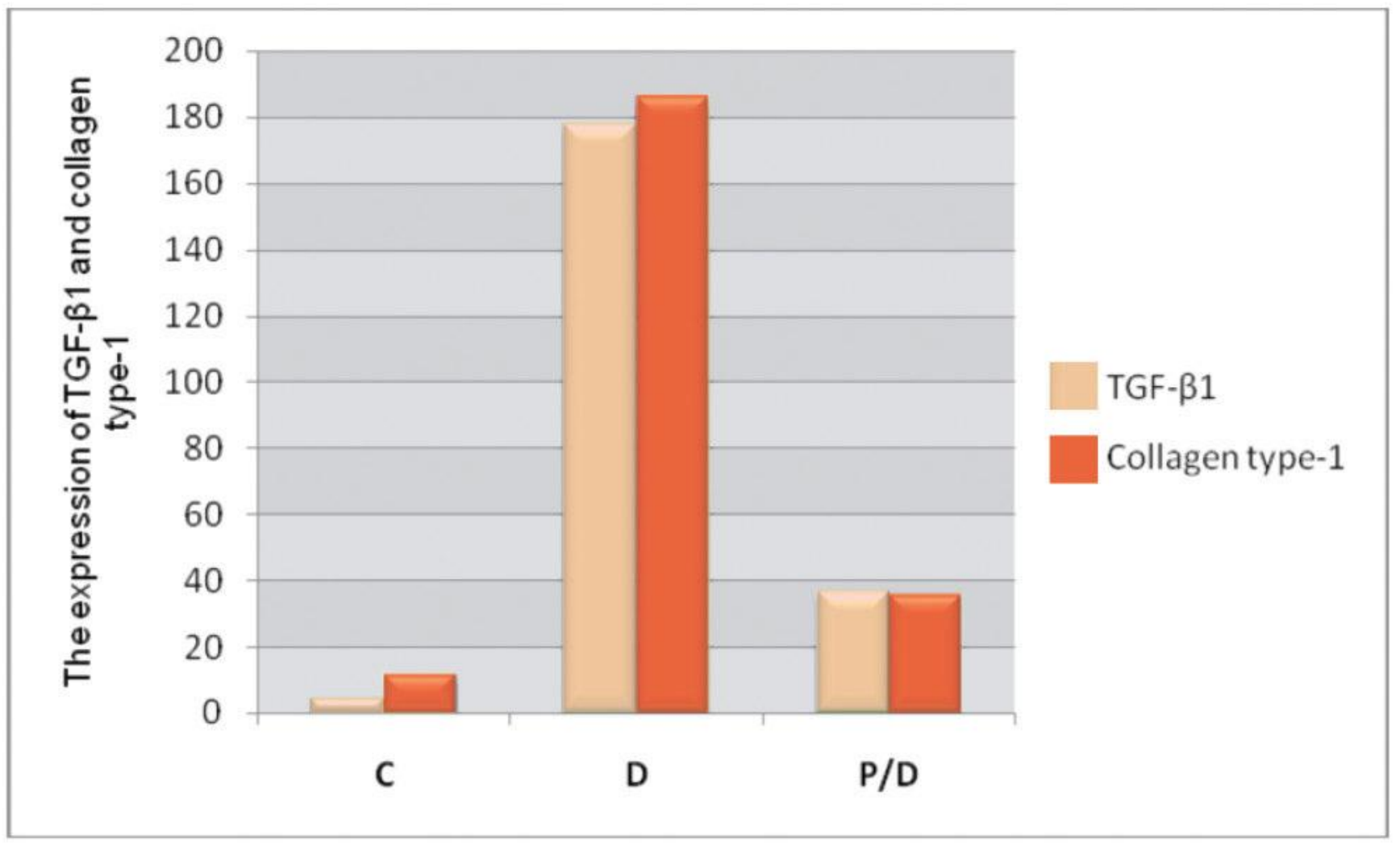

Figure 1. The expression of TGF- $\beta 1$ and Collagen Type-1 in each group

C, control; D, DXR induced nephrotoxicity; P/D, effect of PTX on DXR $p<0.001$ for C vs. D and $p<0.005$ D vs. P/D for both expression of TGF- $\beta 1$ and Collagen type-1.
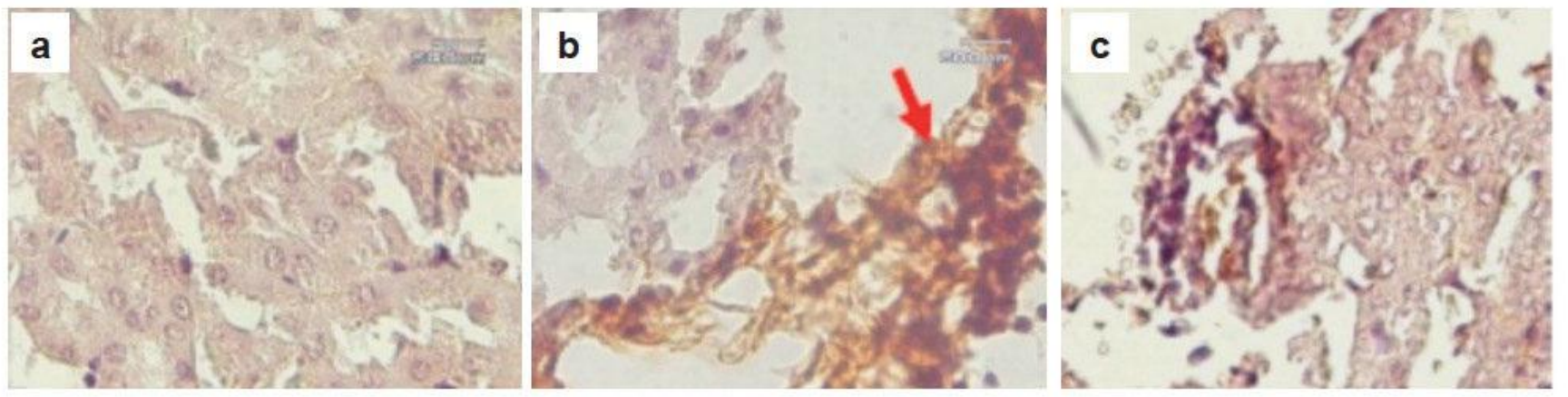

Figure 2. Comparative description of protein TGF- $\beta 1$ which was expressed by macrophage cells among different groups. Expression of protein TGF- $\beta 1$ on membrane in the macrophage cells appeared to be brown silver (arrows), respectively for (a) the C group, (b) D group, and (c) P/D group (Staining immunohistochemical; 400x magnification Olympus BX-50 M highly significant odel BX-50F-3. Pentax Optio 230 Digital Camera 2.0 Megapixel).

The results showed that mean of Collagen type-1 expression was higher significantly in DXR as compared to $\mathrm{C}(186.25$ vs. $12.00 ; \mathrm{p}<0.001)$; and addition of PTX to DXR showed significantly lower expression than in DXR (36.00 vs. 186.25; $\mathrm{p}<0.001$ ) (Figure 1 ).
The findings of collagen type- 1 expression 8 after treatment, assessed by immunohistochemical examination on membrane of fibroblast cells using a light microscope are shown in Figure 3. 

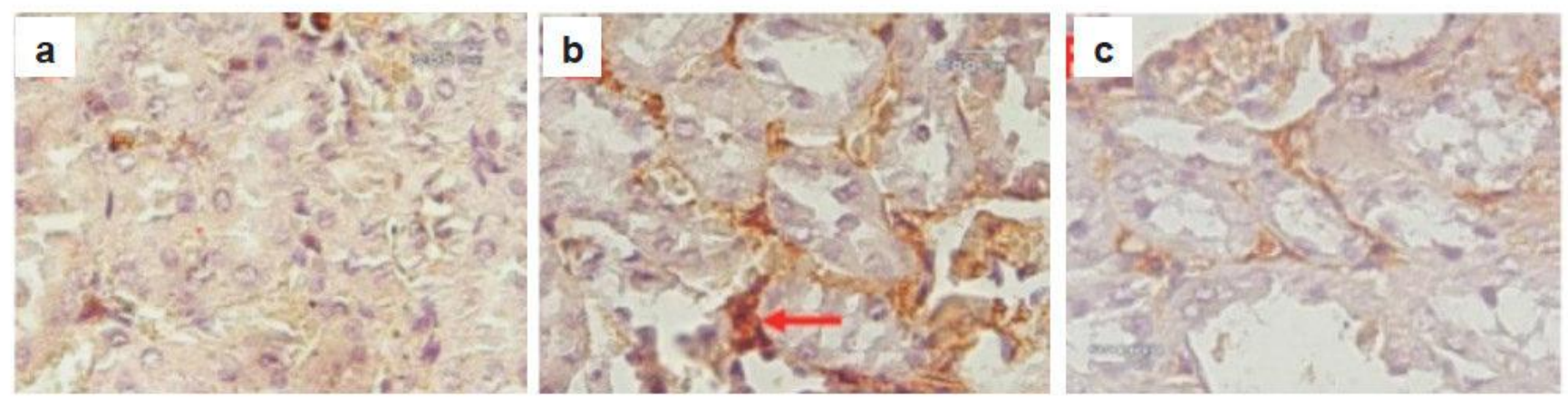

Figure 3. Comparative pictures of protein collagen type-1 which were expressed by cells located in fibroblast renal interstitial compartment between various different treatment group. Collagen type-1 expression in membrane fibroblast cells appeared to be brown silver (arrows), respectively for (a) the $\mathrm{C}$ group, (b) D group, and (c) P/D group. (Staining immunohistochemical; 400x magnification Olympus BX-50 Model BX-50F-3. Pentax Optio 230 Digital Camera 2.0 Megapixel).

\section{Renal Interstitial Fibrosis}

The result showed that mean of interstitial fibrosis was higher significantly in DXR as compared to C (85.00 vs. $16.75 ; \mathrm{p}<0.001)$; and addition of PTX to DXR showed significantly lower than in DXR ( 60.50 vs. $85.00 ; \mathrm{p}<0.001)$ (Figure 4).
This indicates that addition of PTX to DXR at week 8 after treatment has demonstrated the ability of PTX to suppress the incidence of interstitial fibrosis resulting from administration of the nephrotoxic agent DXR.

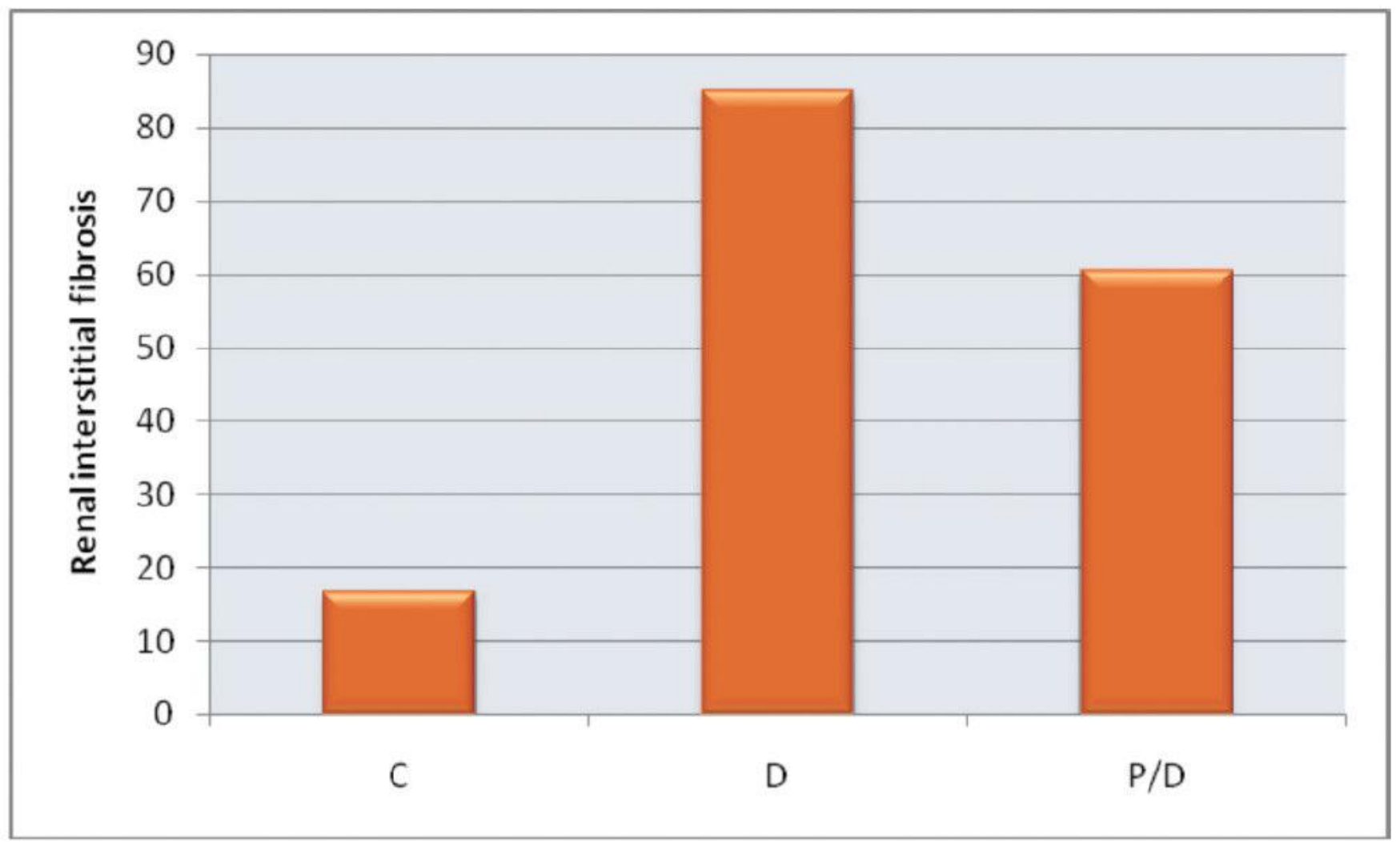

Figure 4. Renal interstitial fibrosis in each group

C, control; D, DXR induced nephrotoxicity; P/D effect of PTX on DXR

$p<0.001$ for $C$ vs. $D$ and D vs. P/D for renal interstitial fibrosis 
Results of the histological examination on interstitial fibrosis by the technique $\mathrm{VvG}$ eight weeks after treatment using light microscope are shown in Figure 5.
PTX acts as an anti-ROS, so that damaged cells (debris) are reduced, and consequently the stimulation of macrophages through TLR-4 is reduced as well. Finally,
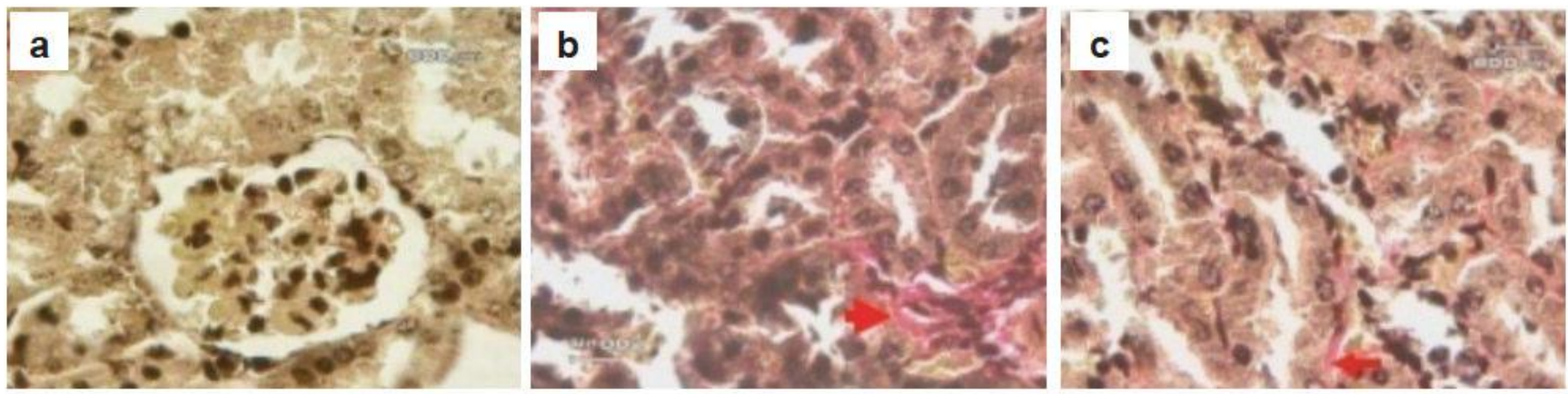

Figure 5. Comparative pictures of interstitial fibrosis among the different treatment.Fibrous tissue appeared to be red (arrow) located between the tubule contortus, respectively for (a) the C group, (b) D group, and (c) P/D group. The growth of fibrous tissue was clearly visible, especially in group P (arrowhead) (Staining Verhouff van Geison; 400x magnification Olympus BX-50 Model BX-50F-3. Pentax Optio 230 Digital Camera 2.0 Megapixel).

\section{Discussion}

The use of DXR to induce nephrotoxic effect in experimental animals has been widely practiced. DXR binds to the membrane receptor of proximal tubule cells. Eventually it stimulates the NADPH enzyme located in the mitochondria and forms ROS. This process is suitable with the initial stage (incubation period/subclinical).

Damage of the kidney tissue can be detected at:

1. Molecular level (Expression of TGF- $\beta 1$ and collagen type-1), which can be examined immunobiologically by immunohistochemistry methods.

2. Cellular level (interstitial fibrosis), as detected from histopathological changes with Verhoeff-van Gieson staining technique.

At emergence stage level, DXR as nephrotoxic material is destructive to kidney cells. The side effect is caused by ROS that is very highly reactive. ROS damages the proximal tubule cells, endothelials, basal membrane, and glomerulus. Damaged cells form debris. Debris activates macrophages through TLR-4, and macrophages will express cytokines such as TNF- $\alpha 1$, TGF- $\beta 1, \Pi L-1 \beta, \Pi L-6$, and IL-8 (2.5).

The binding of TGF- $\beta 1$ to fibroblast cell membrane receptor will stimulate the expression of collagen type-1, and stimulates interstitial fibrosis $(5,6)$.

At active stage level, administration of DXR causes TGF- $\beta 1$ to be more dominant than MMP-9, causing imbalance $(2,11,12,13,14)$. the expression of TGF- $\beta 1$ by macrophages is also reduced. So PTX plays a role in fixing the level of imbalance $(7,8,9,10)$.

This imbalance state will lead to the occurrence of interstitial fibrosis which is caused by collagen type- 1 expression. The occurrence of interstitial fibrosis is an irreversible condition (terminal stage).

\section{EXPRESSION OF TGF-B1}

In this study, TGF- $\beta 1$ expression in kidney tissue in the group of mice induced by DXR as nephrotoxic agents (D) appeared to be higher than in the normal mice as control (C). The significant increase of TGF- $\beta 1$ was already seen at week 4 , and continued induction of DXR increased the TGF- $\beta 1$ expression. Increasing TGF- $\beta 1$ expression due to administration of DXR induces the occurrence of "DXR Iron Complex". DXR Iron Complex will produce ROS that damages the cell structure and then forms debris. Debris stimulates macrophages through TLR-4, thus releases the binding of Nf- $x \mathrm{~B}$ with $\mathrm{I} x \mathrm{~B}$ and hence Nf- $x \mathrm{~B}$ becomes active. Nf- $x \mathrm{~B}$ as a transcription factor causes the macrophages to express a number of pro-inflammatory cytokines, and TGF- $\beta 1(5,6,15,16)$. TGF- $\beta 1$ plays a key role in the formation of renal fibrosis in human and experimental animals. According to Koli et al., protease, thrombospondin-1, ROS, and low $\mathrm{pH}$ are factors that may be able to facilitate activation of TGF- $\beta 1$ in kidney (17). According to Wang et al., TGF- $\beta 1$ binds to active TGF- $\beta$ type-II receptor (TGFR-II), which in turn recruits and activated TGF- $\beta$ type I receptor (TGFR-I) (18). The active TGFR-I stimulates Smad2 and Smad3 to form hetero-oligomeric complexes with Smad4, which would 
be translocated into nucleus to regulate gene transcription target. Many researches have proved that blockade of TGF$\beta 1$ would improve renal fibrosis (4).

The results of this study indicate that the combination of DXR + PTX significantly inhibited the production of TGF- $\beta 1$ nephrotoxicity caused by DXR. Administration of PTX as a nephro-protective agent along with DXR seems to decrease TGF- $\beta 1$. These results are in line with the results of the study by Xiong et al., in which PTX significantly decreased expression of TGF- $\beta 1$ in liver fibrosis (19). PTX is a xanthin derivative, functions as phosphodiesterase inhibitor, can promote the increase of intracellular cAMP, dilation of blood vessels and smooth muscles, and microcirculation improvement. The ability of PTX to reduce TGF- $\beta 1$ expression is possible because PTX either acts as electron donor in oxidation or has the ability to inhibit phosphodiesterase (20). With its ability as an electron donor, PTX may function as an anti-ROS, so that damage of cell structures can be prevented. Preventing damage of cells caused by ROS will lead to reduced debris so stimulation to TLR-4 is also reduced $(8,9,10)$. This situation eventually causes reduced $\mathrm{Nf}-\boldsymbol{x B}$ activity of macrophages, causing expression of cytokine TGF- $\beta 1$ is also decreased $(8,9,10)$. These results bring about further hypothesis that the combination of PTX with DXR inhibits the increase of TGF- $\beta 1$ expression, thus preventing glomerulosclerosis or interstitial fibrosis.

Clinically, PTX has been widely used for the treatment of peripheral and cerebrovascular diseases. PTX can inhibit proliferation and synthesis of glikosaminoglikan and collagen by fibroblast (20). Either PTX can inhibit the proliferation of lymphocyte cells, fibroblasts, and mesangial or can decrease the production of ECM proteins $(21,22)$. PTX also reduces peritoneal fibrosis and formation of postoperative adhesion (20).

\section{COLLAGEN TYPE-I EXPRESSION}

In this study, the result of immunohistochemical examination on kidney tissue of the group of mice induced by nephrotoxic agent (DXR) showed the number of immunoreactive cells on the cell membrane was higher than the control group. From the statistical analysis we found a significant increase of collagen type-I expression.

The group P/D, which was given combination of PTX and DXR, showed lower number of immunoreactive cells on the cell surface than the group D, which only got DXR. The statistical analysis showed there was a significant decrease in collagen type-I expression.

The result showed that TGF- $\beta 1$ expression in group P/D was lower than group (D). With the ability of PTX to inhibit glomerulosclerosis and interstitial fibrosis $(21,22)$, it also decreases the binding of TGF- $\beta 1$ on fibroblast cell membrane receptors $(5,6)$. Reduced binding of TGF- $\beta 1$ on fibroblast cell membrane receptors will decrease the stimulation of collagen type-I expression $(5,6)$. According to our study, the group which was given combination of PTX and DXR might have decreased collagen type-I expression. These results agreed with the findings of the study by Xiong et al., that showed the administration of PTX on hepatic fibrosis animal models could reduce collagen type-I expression (19).

\section{INTERSTITIAL FIBROSIS}

This study showed that group D had increased interstitial fibrosis as compared with group C.

Renal fibrosis is a major determinant of loss of kidney function which causes end-stage renal disease. The development of renal fibrosis is a complicated process that involves in complex-multiple intracellular signal pathways. Route of mitogen-activated protein kinase (MAPK) p38 and TGF- $\beta 1 /$ Smad pathways is important intracellular signal pathways that involve in the production of mediators pro-inflamation and profibrosis, as well as accumulation of ECM products (23). TGF- $\beta 1$ expression levels determine the severity of renal interstitial fibrosis; this study showed that excessive TGF- $\beta 1$ expression would stimulate the growth of interstitial fibrosis. One of the most important of TGF- $\beta 1$ profibrotic effects is the presence of autoinduction in different types of fibroblast cells, which may be responsible for maintaining or strengthening the autocrine as well as paracrine response of TGF- $\beta 1$.

Group P/D showed a significant decrease in interstitial fibrosis at week 8 . This finding was in line with the results of decreased expression of TGF- $\beta 1$ and collagen type-I. Reduction of TGF- $\beta 1$ expression would have an impact on decreasing binding of TGF- $\beta 1$ on fibroblast cell membrane receptors and thus decrease stimulation of collagen type-I expression. This would reduce the interstitial fibrosis (5.6). These results were in accordance with the study by Xiong et al., that showed PTX inhibited hepatic fibrosis through reduction of TGF- $\beta 1$ and collagen type-I expression (19).

Results of recent studies have shown that PTX has been found to be an antifibrotic effect. In vitro experiments explain that PTX could inhibit the fibroblast activity in patients with hepatitis and suppress synthesis of collagen. In the initial stage, treatment with PTX could reduce the hepatic lesion and inflammatory reactions. This shows that PTX could inhibit progression of renal interstitial fibrosis due to side effects caused by the use of DXR.

Based on the epistemology principle, we have found the overall results of our study on DXR effect as nephrotoxic drugs with variables of TGF- $\beta 1$, collagen type-I, and 
interstitial fibrosis. This study was in accordance with the findings of the study by Tamaki et al., (5). But in this study, we have added the administration of PTX as nephroprotective drugs. Our study has revealed that combination of DXR + PTX significantly inhibited variables expression which caused nephrotoxicity.

Generally, the knowledge that combination DXR + PTX can prevent progression of interstitial fibrosis due to DXR administration can give way to prevention of interstitial fibrosis progression, and will reduce cumulative remains of protein metabolism and thus can prevent the occurrence of uremia syndrome.

\section{Conclusions}

PTX was proven to have an effect of preventing the nephrotoxicity effect of DXR through lowering expression of TGF- $\beta 1$ and collagen type- 1 as well as renal interstitial fibrosis.

\section{Acknowledgements:}

We thank Prof Dr Juliati Alsagaff Hood, dr., MS. SpPA (K), FIAC; Prof R. Moh. Yogiantoro, dr., SpPD-KGH, and all the study participants who have facilitated this research.

\section{References:}

1. Lin SL, Chen YM, Chien CT, Chiang WC, Tsai CC, Tsai TJ. Pentoxyphylline Attenuated the Renal Disease Progression in Rats with Remnant Kidney. J Am Soc Nephrol 2002;13: 2916-2929

2. WHO. Cancer. http://www.who.int/cancer (diunduh tanggal 12 Pebruari 2010)

3. Wang Y, Wang YP. Role of CD 8th Cells in the Progression of Murine Adiramycin Neprhropaty. Kidney International 2001;59:941 - 949 .

4. Erlan JF, Desmant. Transfers of Ferritin-Bound Iron to Andriamicyn. FEBS letters 2001;176: 97 - 100.

5. Blobe GC, Schiemann WP, and Lodish HF. Role of Transforming Growth Factor $B$ in Human Disease. N Engl J Med 2000;343(3):1350-58.

6. Tamaki K, Seiya O, Takashi A. TGF- $\beta$ in Glomerulosklerosis and Interstitial Fibrosis, of Andriamicyn Neprhopaty. Kidney International 1994;45:525 - 536.

7. Suryohudoyo P. Oxidant, Anti-oxidant and Free Radical (Oksidan, Anti-okisdan dan Radikal Bebas). Selected Topics. Molecular Medicine. CV Agung Seto. Jakarta. 2000:31-47.
8. Kupsakova, Docolomansky P, Ryber M, Brier A. Carbonyl Group of Aliphatic Side Chain on Pentoxyphylline does not Play Role for P.Glycoprotein Antagonizing Effect of Pentoxyphylline. Gen Physol Biophys 2002;21: 471-8.

9. Mayes PA. Structure and Function of Lipofilic Vitamin. Harpers Biochemistry. 25th edition. 2003:613-622.

10. Davila ME, Esqueda, Martinez F, Morales. Pentoxyphylline Diminshes the Oxidative Damage to Renal Tissue Induced Shreptotozocin in Rat. Experimental Diab Res 2004;5: 245-251.

11. David D and Abbe S. Protective Effect of Recombinant Human Interlukin-1a in Doxorubicin Treated Normal and Tumor Bearing Mice. Cancer Research 1993;S3:1565 - 1570.

12. Belloc F and Dumani P. Effect of Pentoxyphylline on Apoptosis of Cultural Cells. J.Cardiovase Pharmacal 1995;25:7174.

13. Sankar. Handbook of Transcription Factor NF Kappa B Bocca Rator.CRC ISBN 8493 - 2006;2794 - 6.

14. Guntur AH. SIRS and SEPSIS: Immunology, Diagnosis, and Management (SIRS dan SEPSIS: Imunologi, Diagnosis, Penatalaksanaan). Sebelas Maret University Press. Surakarta. 2006

15. Onat A, Can G, Hergenc G, Yazici M, Karabulut A, Albayrak S. Serum Apolipoprotein B Predicts Dyslipidemia, Metabolic Syndrome and, in Women, Hypertension and Diabetes, Independent of Markers of Central Obesity and Inflammation. International Journal of Obesity 2007; 31: 1119-1125.

16. Sakai N, Uchida $\mathrm{Y}$, Ohashi $\mathrm{K}$, et.al. Measurement of Fasting Serum apoB-48 Levels in Normolipidemic and Hyperlipidemic Subjects by ELISA. Journal of Lipid Research 2003; 44:1256-1262.

17. Baratawidjaja KG dan Iris R. Basic Immunology (Imunologi Dasar). $8^{\text {th }}$ Edition University of Indonesia. 2009

18. Koli K, Saharinen J, Hyytiainen M, Penttinen C, Keski-Oja J. Latency, activation, and binding proteins of TGF-beta. Microsc Res Tech 2001;52:354-362.

19. Wang W, Koka V, Lan HY. Transforming growth factor-beta and Smad signalling in kidney diseases. Nephrology (Carlton) 2005;10:48-56.

20. Gameson R and Reeves WB. TNF-a Mediates Chemokine and Sitokine Expression and Renal Injury in Cesplation Nephrotoxcity. J. Clin Invest 2007; 110: 835-842.

21. Xiong LJ, Zhu JF, Luo DD, Zen LL, Cai SQ. Effects of pentoxyphylline on the hepatic content of TGF-b1 and collagen in Schistosomiasis japonica mice with liver fibrosis. World J Gastroenterol 2003;9:152-154

22. Fang CC, Lai MN, Chien CT, Hung KY, Tsai CC, Tsai TJ, and Hsieh BS. Effects Of pentoxyphylline On Peritoneal Fibroblasts And Silica-Induced Peritoneal Fibrosis. Peritoneal Dialysis International 2003;23: 228-236.

23. Strutz F, Heeg M, Kochsiek T, Siemers G, Zeisberg M, Muller GA. Effects of pentoxyphylline, pentiphylline and gamma-interferon on proliferation, differentiation, and matrix synthesis of human renal fibroblasts. Nephrol Dial Transplant 2000;15:1535-1546.

23. Li J, Campanale NV, Liang RJ, Deane JA, Bertram JF, and Ricardo SD. Inhibition of p38 Mitogen-Activated Protein Kinase and Transforming Growth Factor- $\beta 1 /$ Smad Signaling Pathways Modulates the Development of Fibrosis in Adriamycin-Induced Nephropathy. Am J Pathol 2006;169: 1527-1540. 